\title{
Weighted Product Method in the Value Engineering Process for Construction Project
}

\author{
Joel Ochieng' Wao \\ Department of Construction Science, Tuskegee University, Alabama, USA
}

\begin{abstract}
:
Value engineering (VE) as a strategic multidisciplinary methodology involves application of techniques that can provide the needed value to project owners. Arriving at this value may require different evaluation tools such as goal programming, weighted product method, utility function, among others. These tools have advantages and disadvantages that may prescribe their respective usages in projects. This research utilized the weighted product method in the evaluation of alternatives for a construction project after considering the project owner's requirements. The method was selected because of its ease of use and ability to turn qualitative data into quantitative information. It was hypothesized that this method would provide the project owner with the needed value in the project. Different alternatives were developed and evaluated to select the preferred one. Results showed good outcome that was accepted by the project owner. It was concluded that weighted product method would be a worthwhile inclusion in the VE methodology to evaluate alternative systems developed to meet project goals, and this supported the hypothesis. Difference in preference by project owners was noted as a potential limitation in the use of the method and so it was recommended that further investigation be conducted that employ other evaluation techniques such as utility theorem or analytical hierarchy process to validate the method.
\end{abstract}

Keywords: Construction Project, Multi-Criteria Decision Making (MCDM), Weighted Product Method, Value Engineering.

\section{Introduction}

Value engineering (VE), value methodology, value planning, value analysis and value management are terms that are used interchangeably in the field of construction. The terms focus on the guidelines of value analysis methodology (also known as the VE job plan) and has function analysis as part of the process (Wao, 2014). Decision making in VE begins from function analysis of systems to evaluation of alternatives in projects.

Society of American Value Engineers (SAVE)-International (2015) and Wao (2015) defined VE as a systematic application of refined techniques that identify the function of a system using teamwork, creative approaches and good communication by multidisciplinary team to develop systems that meet the needs of the project owner at the lowest cost and highest performance and quality standards. Good team effort and understanding, superior system performance and optimal cost are key goals in any VE process. Alternative systems must be developed carefully before selecting those that are most preferred for a particular project.

Selecting the alternative requires creativity and free flow of ideas. The team leader who drives the VE team to engage in in-depth analysis of systems that consider their functions, owner's goals and using appropriate evaluation technique to find the most preferred alternative guides this. Using incorrect method may result in a decision that does not meet or compromise the owner's requirements and ultimately lead to project failure and owner disappointment. VE employing appropriate evaluation method would ensure that project goals are met satisfactorily.

Various decision-making methods can be used with VE in construction projects. They can be called multi-criteria decision-making methods (MCDM) because they employ different sets of criteria in the decision 
process. They may include goal programming, utility theory, weighted sum method, weighted product method, analytical hierarchy process, among others. Each has its advantages and disadvantages.

Project team should employ evaluation methods that are fast to use to deliver project goals or outcomes on time and at preferred optimum cost and high quality/performance standards. This paper presented a a VE process that utilized weighted product method in evaluating alternatives for a construction project. The method was employed because it uses relative measures (which are similar to human subjective and ever-changing decision process) rather than actual or unit measures making it user friendly (Triantaphyllou et al., 1998). This method speeds up the VE process to arrive at solutions that are pleasing and provide value to the owner.

\section{Literature Review}

VE process was originally formulated by Lawrence Miles in 1947 to aid in meeting the needs at General Electric where they faced scarcity of resources to produce products. Miles, with the idea of value and management, developed function analysis concept that later became a process that significantly transformed the field of VE. Today, VE is applied in many areas including projects that are complex, costly, repetitive, or those that are likely to implement design changes (Chen et al., 2010; Wao et al., 2016; Wao, 2017). VE process involve development of alternatives with the most preferred being selected for inclusion in the project.

Two VE methodologies can guide practitioners in conducting value analysis of systems. SAVE International standard job plan and the American Society for Testing and Materials (ASTM) standard E169914, also known as the Standard Practice for Performing Value Engineering (VE)/Value Analysis (VA) of Projects, Products and Processes are typically used (Wao, 2015). Following the job plan ensures completion of VE study that is characterized by selecting the alternatives that meet owner's requirements. The VE study begins from the pre-study phase and ends at presentation to the owner who then decides on the options selected.

Figure 1 shows the SAVE International job plan. This standard or job plan was developed in 1997 and has been revised to reflect paths for value improvement.

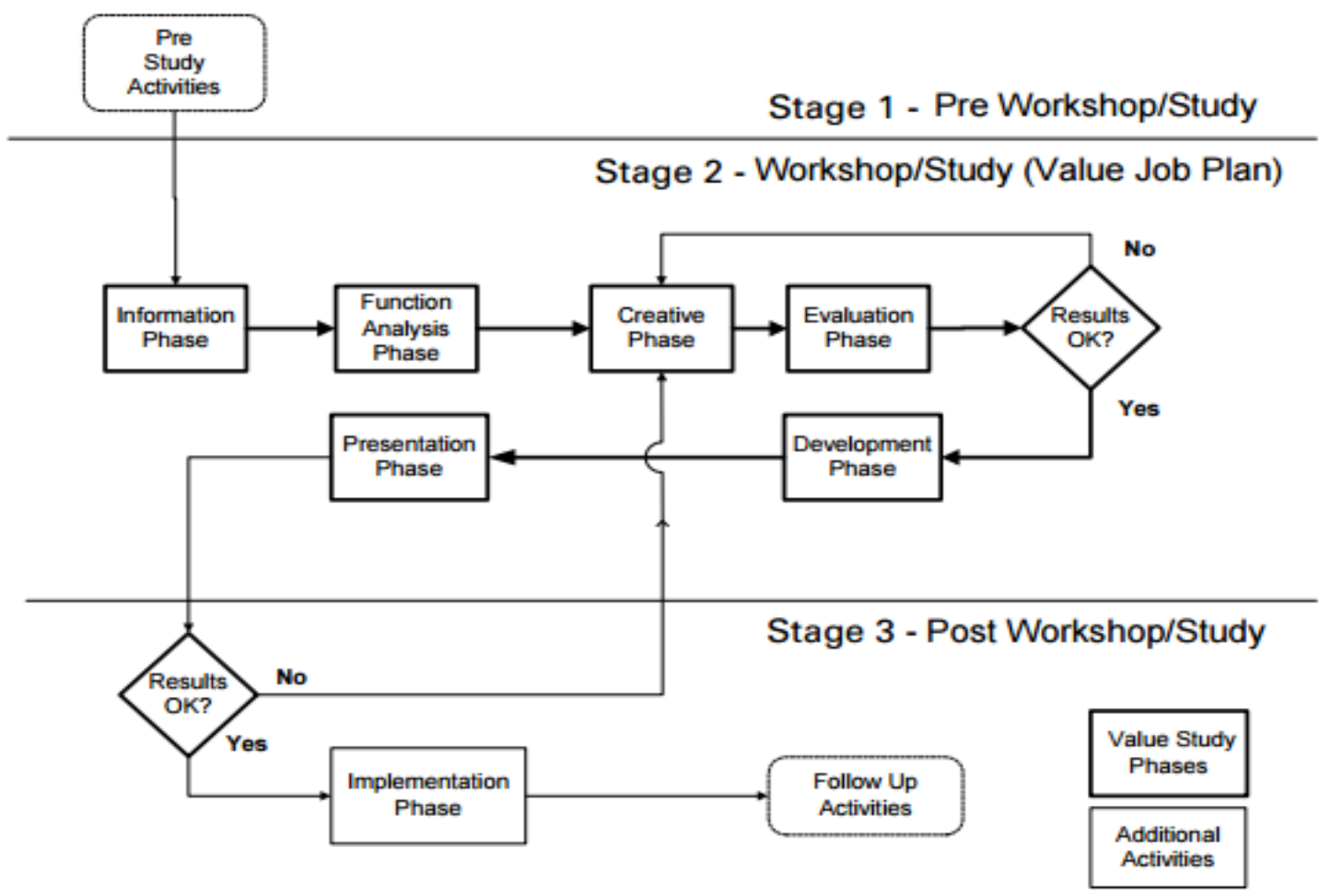

Figure 1. SAVE International Value Standard (2015).

The success of the VE methodology or job plan require good teamwork and communication. The steps or job plan are as described below according to Wao (2017). 
- Information phase: The problem is identified and information about it is gathered. The resources needed to solve the problem are determined and allocated appropriately.

- Function analysis phase: VE team identifies and analyzes functions. They determine the worth and implications using the owner's requirements. Reviews of functions are conducted to determine those that may need to be eliminated, improved or re-created to meet project goals.

- Creative phase: Ideas are developed through brainstorming. From the listed ideas, potential options are generated.

- Evaluation phase: Structured evaluation process is followed to select ideas that have potential for value improvement while delivering the project's function(s) together with the performance and quality requirements. The alternatives developed are analyzed and evaluated. The evaluation criteria are listed including the advantages and disadvantages of each alternative. A ranking procedure is established where the top ranked is considered the best alternative.

- Development phase: The best alternative is selected and its feasibility determined. This includes initial estimated costs, life cycle costs, and technical information.

- Presentation phase: The VE team presents the alternatives developed to the design or construction team and/or the owner to understand fully the importance of the alternatives generated before final implementation. A written report is prepared which shows the cost savings in addition to other supporting information. Effective communication is key here.

The above steps require systematic application of techniques especially in the critical stages of the VE job plan. For example, Function Analysis System Technique (FAST) is an important tool for achieving the best value of a project through critical analysis and definition of functions of systems (Bytheway, 2007). Ideally, function analysis is the beginning of the critical steps of the value analysis process and so it needs to be fully structured and well implemented to ensure project success.

There is also the evaluation of alternatives that if well executed with proven tools would result in better decisions and selection of alternatives for a project. There are many different criteria involved in making decisions hence the MCDM employed in VE. Rajak et al. (2015) conducted a study assessing the integration of MCDM and VE concept in vender selection in which the process proved worthwhile. However, the study did not specify which type of MCDM was used to arrive at the final solution. Niraj (2011) investigated some of the selection practices through VE especially in maintenance projects. Noteworthy is that weighted product method was cited to be potentially better due to its simplicity and user-friendliness (Triantaphyllou et al. 1998; Wao, 2015). Thus, a VE study was initiated using the weighted product method to evaluate and construct wall partition system that meet the needs of the project owner. A research method was developed for the study.

\section{Research Methods}

This research aimed at finding an appropriate evaluation method that would provide value to the project owner and demonstrating the process to meet the project requirements or value propositions. It employed a case study project and MCDM in the VE methodology. It followed the VE job plan from start to the construction phase. It was hypothesized that the alternatives selected by the composite VE method (job plan with weighted product method) would provide solutions that were acceptable. This would promote or enhance wider usage of the VE approach to provide high performing/quality projects. Next is the description of the job plan employed.

\subsection{Pre-workshop Phase}

\subsubsection{Coordinating the project and schedule}

Project owner (a representative from a school) contacted the project team to assist in developing and constructing wall partitions in one of the office spaces in the school. There were visits to the project site to familiarize with the project details. The team members had no specific time constraint and so they worked together for about two months. They believed that the time interval was substantial in developing the wall partition options and conducting the analysis needed to give the owner the best possible worth of their investment. 


\subsubsection{Project characteristics and background data search}

The project required analyzing the available office space to fit partition wall(s) on the building space of 257.83 square feet (22.42' x 11.5'). Specifically, the owner required a space for front desk receptionist, a copier at a corner and two other separate office spaces (three workstations), including two options of wall partition systems to choose.

The team performed background data search on the possible alternatives for the building partition wall. Specifically, the research was to determine the characteristics of each alternative wall partition system. In addition, they reviewed different manufacturers' specifications and cut-sheets of possible partition systems to determine viable options to use. In doing this, they had to find feedbacks and/or reports from past and current consumers of the same building systems to evaluate possible impacts when used in the building.

\subsubsection{Coordination meeting and project constraint}

Periodic meetings with the owner were held to get more information, clarification of questions and to ascertain that everything was as per the owner's system performance/quality requirements. Site measurements were taken that were later used in determining the exact locations of the needed partitions in the space.

The project was constrained by the space availability. The three office spaces were to fit in the 22.42 ' by $11.5^{\prime}$ area and had to accommodate an office printer (or copier) at the front corner (refer to the floor plan in Figure 3 for more details). The school building was considered a sustainable building and so the selected systems for inclusion into the office space had to meet some sustainability requirements as prescribed by the Leadership for Energy and Environmental Design (LEED), the sustainable building assessment tool. The project required the use of systems or options that meet the performance requirements that entailed durability, acceptable first cost, flexibility for future expansion or changes, sustainability and aesthetics. The analysis team considered these performance requirements in the VE evaluation of the options.

\subsection{Workshop Effort}

\subsubsection{Project data}

After the initial job site visit, project information including measurements and pictures were collected. The site measurements were translated into a floor plan and then distributed to the team during the first development meeting. The team discussed and determined the exact location of the partition systems of length 6', 7' and 7' as shown in the floor plan in Figure 2.

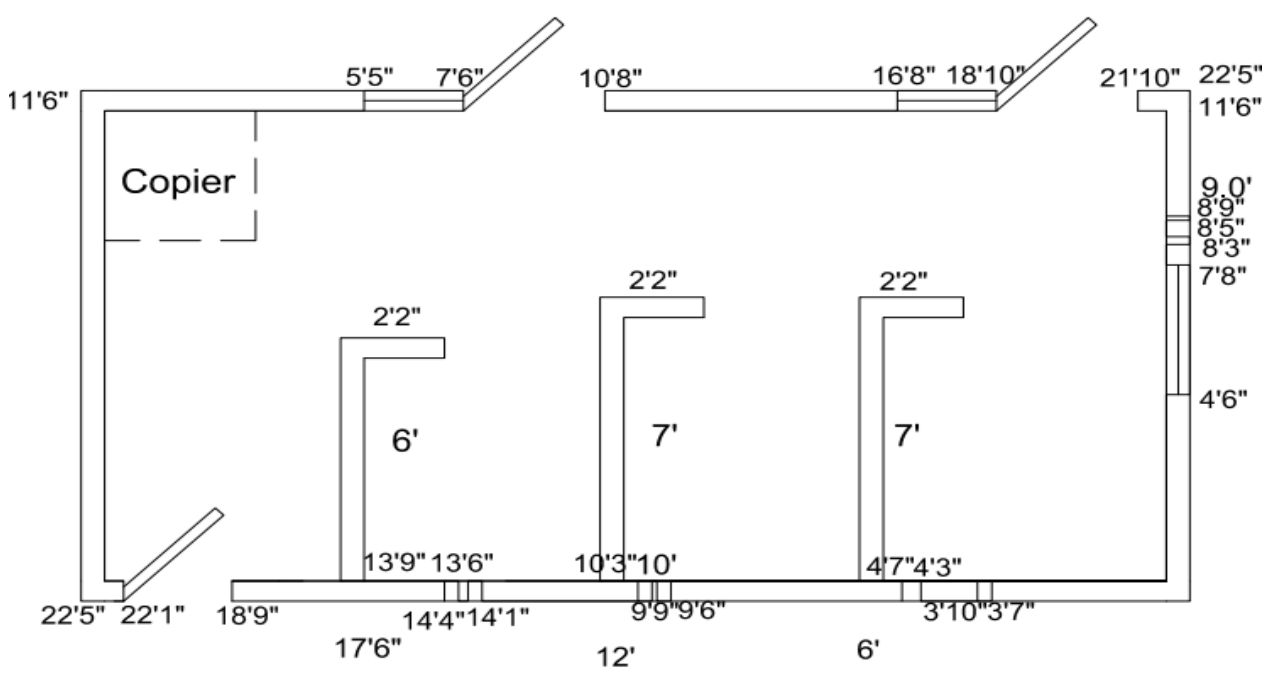

Figure 2. Floor plan of the building space showing location of the partition walls. The dimensions (in inches) are incremental from one end to the other as shown.

Team members were advised by the VE team leader to collect as much data as possible including the possible sustainability considerations for the alternatives, in addition to their advantages and disadvantages. 


\subsubsection{Information phase (discussing the owner's requirements) and function analysis}

The team met with the owner, identified the requirements, and prioritized the key performance criteria for the project. These included maintainability, first cost, durability, flexibility, sustainability, and aesthetics. These provided the basis for creativity and evaluation of the different options needed by the project owner. This was important as it provided avenues for reducing cost while maintaining or improving performance and/or quality requirements. In essence, the team had to find cheaper ways to provide similar functions of the partition systems while maintaining or improving their expected performance or quality levels.

\subsubsection{Creative thinking and brainstorming phase}

At this stage, the team were encouraged to brainstorm about the possible systems for consideration. Free flow of ideas was encouraged and judgment was delayed until the list of ideas had been exhausted. Discussion of some ideas led to development of other ideas, and so on until the team felt that nothing else would come up.

After several iterations in the process, two possible alternatives for the partition wall system were developed while eliminating the impractical ones. These were the built-in partition wall system and the manufactured fabric wall partition. The two formed the basis for the VE evaluation phase of the project.

\subsubsection{Evaluation phase}

After various considerations, the characteristics of the alternatives were developed for use in the evaluation phase. These included;

\section{Built-in partition wall}

The partition wall was to be built onsite and comprised of steel frame studs that are highly durable for a longer life span of the intended structure. The wall was to be enclosed with fire rated drywall, and smoothly painted to give the needed finished facade. This option was durable, cost effective and provided a sustainable solution.

\section{Manufactured fabric partition wall}

This partition type was to be bought fully prefabricated and installed onsite as required. They had great flexibility, durable, usually fabric and could be rearranged at any time. Even though it allowed for more flexibility, it had a relatively higher cost compared to the built in type. It also had problems with sustainability.

A set of criteria were developed, weighted, and a quality model was developed to further analyze the partition system. The criteria developed aligned with the requirements of the owner. Once the criteria were established, weights were assigned to each criterion with rates ranging from 1-5 points. These ratings, dubbed weighted importance, were established after in-depth discussions and consensus by the team. A rating of 1 implied least important while 5 was most important. Table 1 shows the criteria weights for the partition system.

Table 1. Weighting of criteria

\begin{tabular}{|c|c|l|}
\hline Criteria label & Criteria description & Weighted importance (1-5) \\
\hline a. & Maintainability & 3 \\
\hline b. & First cost & 5 \\
\hline c. & Durability (Lifespan) & 4 \\
\hline d. & Sustainability & 5 \\
\hline e. & Flexibility & 4 \\
\hline f. & Aesthetics & 4 \\
\hline
\end{tabular}

It can be inferred from Table 1 that most of the criteria had high importance for the wall partition. Maintainability was at moderate in which case it was expected that the material selected needed not to experience much maintenance if it was to be durable enough. Sustainability and overall cost of the project were rated highly implying they were those areas the owner placed highest importance considering other criteria. 


\subsubsection{Quality model and pairwise comparison of criteria}

The weighted importance were best shown in the quality model. Quality model (scale: 1-5) is shown in the radar graph in Figure 3 with specific weights of each criterion. This graph provided a good representation of the weighted importance of the criteria for the project system.

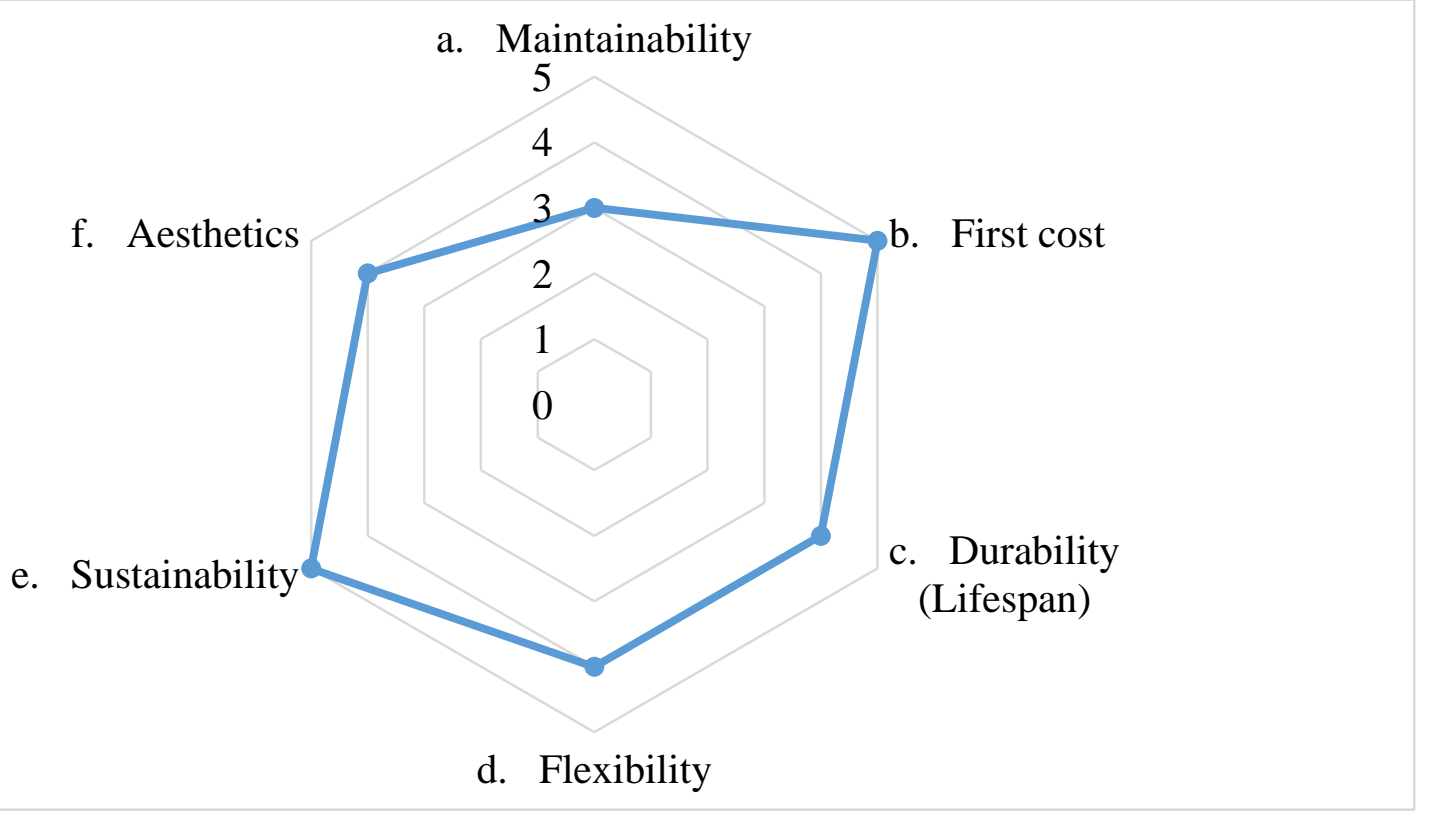

Figure 3: Radar graph showing relative importance of criteria

Pairwise comparison of criteria was then conducted to show how each criterion related to the other in the order of preference. For example, first cost with a rating of 5 compared with durability rated 4 in importance would give a value of 1 by subtraction; implying there is 1 unit likelihood of considering an alternative with lower first cost. First cost and flexibility when compared gave a zero (0) but the value recorded was 1 ; implying that one system would have to be selected when presented with two alternatives of equal importance. Deductively, those criteria that gave negative values when paired had zero recorded implying that there would be no preference in such cases. A summation for each pairwise comparison of criteria were presented in Table 2 .

Table 2. Pairwise comparison of weighted criteria

\begin{tabular}{|c|c|c|c|c|c|c|c|}
\hline & $\mathrm{a}$ & $\mathrm{b}$ & $\mathrm{c}$ & $\mathrm{d}$ & $\mathrm{e}$ & $f$ & Summation \\
\hline $\mathrm{a}$ & - & 0 & 0 & 0 & 0 & 0 & 1 \\
\hline $\mathrm{b}$ & 2 & - & 1 & 1 & 1 & 1 & 6 \\
\hline $\mathrm{c}$ & 1 & 0 & - & 0 & 1 & 1 & 3 \\
\hline $\mathrm{d}$ & 2 & 1 & 1 & - & 1 & 1 & 6 \\
\hline $\mathrm{e}$ & 1 & 0 & 1 & 0 & - & 1 & 3 \\
\hline $\mathrm{f}$ & 1 & 0 & 1 & 0 & 1 & - & 3 \\
\hline
\end{tabular}

\subsubsection{Performance rating of alternatives}

Each of the two alternatives developed was assessed separately using the criteria generated for the evaluation of the wall partition system. Likert scale with scores from 1-5 was used to determine how each alternative would rate for each of the different criteria (also known as the performance or quality criteria). The rating of 1 implied least performance/preferred and 5 implied most performance/preferred. The results of the performance ratings of the two alternatives as conducted by the team were presented in Table 3.

Table 3. Performance rating of each of the alternatives

\begin{tabular}{l|l|l} 
Criteria & Alt. 1: Built-in partition wall & Alt. 2: Manufactured fabric partition wall \\
\hline
\end{tabular}




\begin{tabular}{|l|l|l|}
\hline a. Maintainability & 5 & 4 \\
\hline b. First cost & 4 & 1 \\
\hline c. Durability & 3 & 4 \\
\hline d. Sustainability & 5 & 4 \\
\hline e. Flexibility & 1 & 5 \\
\hline f. Aesthetics & 4 & 3 \\
\hline
\end{tabular}

\section{Results}

The performance scores for each of the alternatives as shown in Table 3 were then used alongside the pairwise comparison analysis in Table 2 to determine the total importance score for each alternative (Table 4). Specifically, the analysis utilized the weighted product method of evaluation where the performance rating for each of the alternatives from Table 3 were multiplied by the summation score of each of the criteria from Table 2 to arrive at the weighted product score for that particular criterion. The total weighted product sum of scores for each of alternatives was then calculated and provided at the bottom (Table 4). The total sum, also called total importance score, was compared for the two alternatives to arrive at the more preferred alternative. Table 4 shows the summary of the evaluation process using the weighted product method in VE.

Table 4. Selecting the best alternative using the weighted product method

\begin{tabular}{|l|l|l|l|l|l|l|l|l|l|l|l|}
\hline \multicolumn{9}{|l|}{ Pairwise comparison of criteria } & \multicolumn{2}{l|}{ Built-in Partition Wall } & \multicolumn{2}{l|}{$\begin{array}{l}\text { Manufactured Partition } \\
\text { Wall }\end{array}$} \\
\hline & a & b & c & d & e & f & Sum & $\begin{array}{l}\text { Performance } \\
\text { Rating }\end{array}$ & $\begin{array}{l}\text { Weighted } \\
\text { Product }\end{array}$ & $\begin{array}{l}\text { Performance } \\
\text { Rating }\end{array}$ & $\begin{array}{l}\text { Weighted } \\
\text { Product }\end{array}$ \\
\hline a & - & 0 & 0 & 0 & 0 & 0 & 1 & 5 & 5 & 4 & 4 \\
\hline b & 2 & - & 1 & 1 & 1 & 1 & 6 & 4 & 24 & 1 & 6 \\
\hline c & 1 & 0 & - & 0 & 1 & 1 & 3 & 3 & 9 & 4 & 12 \\
\hline d & 2 & 1 & 1 & - & 1 & 1 & 6 & 5 & 30 & 4 & 24 \\
\hline e & 1 & 0 & 1 & 0 & - & 1 & 3 & 1 & 3 & 5 & 15 \\
\hline f & 1 & 0 & 1 & 0 & 1 & - & 3 & 4 & 12 & 3 & 9 \\
\hline
\end{tabular}

\subsection{Eliminating impractical ideas and selecting better idea for implementation}

The weighted sum of scores was evaluated and any low scoring alternative was rejected. Even though the scores were not far apart, 70 and 83, the team had all the reasons to conclude that built-in partition wall system would be a better option to provide the needed value. The VE team made the recommendation to the project owner to consider it for installation. The inclusion of this wall partition system was interpreted as having valuable implication to the project owner. The project owner accepted the alternative as it had high potential to provide the needed value, which its subsequent construction proved that the required value was met by the team. Its construction was completed in 2018, 2 years after acceptance of VE results by the owner in December 2015.

\section{Discussion and Conclusion}

VE as a strategic multidisciplinary tool can be applied in many areas. This paper presented a scenario where it was conducted in a small construction project to meet the needs of the project owner. It involved analysis of functions of systems, generated practical alternatives through creative approaches and using proven method to evaluate and select valuable alternative for implementation in the project. Literature review identified various methods such as goal programming, weighted product methods, utility theorem, among others, as some of the MCDM tools that could be used to assess systems during VE evaluation phase. This paper utilized the weighted product method in the VE job plan to select a better wall partition system.

Arriving at the final solution for the project was easy and simple, and that aligned with the research by Triantaphyllou et al. (1998) that concluded that the weighted product method of MCDM approach can be user friendly when implemented consistently. The results of the project met the owner's needs and that showed the 
reliability of the MCDM in making decisions when used in the VE methodology, just similar to the outcome of the research by Rajak et al. (2015). This project outcome showed that VE could be an important tool in making key decisions in construction projects and that aligned with the outcome of the study conducted by Chen et al. (2010). Thus, the hypothesis of the weighted method being worthwhile to the owner by providing valuable project outcome was highly supported.

The process also involved turning qualitative or subjective data into objective or quantitative information that could be easily used in making decisions faster. The approach could be worthwhile in upper managerial positions in the construction industry or professions where multi-objective decisions need to be made quickly and correctly without much risk because risks could pose serious consequences if not well assessed and addressed in advance. VE is one tools that can be used in this endeavor and a reliable evaluation tool would be even better in this quest.

In spite of the valuable outcome of this study, it can be argued that preferences that led to the results may be different from one person to the other, which may affect the validity of the weighted product method. It is therefore important to recognize the difference in preferences as a potential limitation of the method. This may pose a scenario where it would be important to find ways to ensure reliability of the method in various VE applications in projects, products or services.

To validate further the weighted product method as a decision tool in VE, other multi-criteria decisionmaking tools such as goal programming, analytical hierarchy process or utility theory may be applied in similar projects to validate the outcome. Further research may involve similar validity or reliability studies.

Overall, this study showed the use of weighted product method in the VE process to fulfil owner's project requirements. The study provided the methodology that showed useful results that end with superior inclusion in the project. Researchers, construction professionals or project owners could use the method since it has shown its worth by meeting project requirements and providing the needed value in the construction project.

\section{Acknowledgement}

Appreciation goes to the Construction Science and Management (CSM) students at Tuskegee University for helping in this project, especially Ethan Roberts and Aleeyah Sanders who assisted in the plan development, overall evaluation process and presentation to the project owner. Also, Mr. Rogers Hunt III and Mr. William 'Bob' Lewis who led the construction process, and Dr. Raymon Shange and Miles Robinson who oversaw the project from start to the end. Final gratitude goes to Dr. Walter Hill for funding the project at the Carver Integrative Sustainability Center at Tuskegee University.

\section{References}

[1] American Society for Testing and Materials (ASTM E1699-14). "Standard practice for performing value engineering (VE)/value analysis (VA) of projects, products and processes."

[2] Bytheway, C. (2007). "FAST creativity and innovation: Rapidly improving processes, product development and solving complex problems," Retrieved December 19, 2018 from http://www.fastcreativity.com/charlesbytheway.html

[3] Chen, T., Chang, P., \& Huang, Y. (2010). "Assessing the overall performance of value engineering workshops in construction projects", International Journal of Project Management, 28, 514-527.

[4] Miles, L. (1947). "The cost problem and the value engineering approach."

[5] Niraj, M. (2011). "Selection of maintenance practice through value engineering", International Journal of Scientific \& Engineering Research, vol.2, issue 22.

[6] Rajak, A., Niraj, M. \& Kumar, S. (2015). "Multicriteria decision making method \& value engineering-a new concept in vender selection”, International Journal of Current Advanced Research, 4 (7), 171-173.

[7] Triantaphyllou , E., Shu, B., Sanchez, S. \& Ray, T. (1998). "Multi-criteria decision-making: An Operation Research Approach", Encyclopedia of Electrical and Electronic Engineering, John Wiley \& Sons, New York, 15, 175-186.

[8] Value methodology standard (2015). Society of American Value Engineers (SAVE)-International. Retrieved December 19, 2018 from https://c.ymcdn.com/sites/value-eng.siteym.com/resource/resmgr/Standards_Documents/vmstd.pdf 
[9] Wao, J. O (2014). "Value engineering methodology to improve building sustainability outcomes", Dissertation Presented at the University of Florida, Gainesville, USA. Retrieved December 20, 2018 from http://search.proquest.com/docview/1645427857

[10] Wao, J.O. (2015). "A review of the value engineering methodology: Limitations and solutions for sustainable construction", Paper Presentation at the $55^{\text {th }}$ SAVE International Value Summit, San Diego, California, June 7-9, 2015. Retrieved December 18, 2018 from www.researchgate.net/publication/279298044_A_Review_of_the_Value_Engineering_Methodology_Li mitations_and_Solutions_for_Sustainable_Construction DOI: 10.13140/RG.2.1.5183.0884

[11] Wao, J., Ries, R., Ian, F. and Kibert, C. (2016). "Refocusing value engineering for sustainable construction", Paper Presentation at the Associated Schools of Construction Proceedings of the 52 Annual International Conference, Brigham Young University, Provo, Utah, April 13-16, 2016. Retrieved December 18 , 2018 from https://www.researchgate.net/publication/304549946_Refocusing_Value_Engineering_for_Sustainable_ Construction

[12] Wao, J. 2017. "Enhancing the Function Analysis and Identification Phase of the Value Engineering Methodology", $57^{\mathrm{TH}}$ SAVE International Annual Conference: SAVE Value Summit, Philadelphia, PA, USA, August 25-30, 2017. Retrieved December 20, 2018 from https://www.researchgate.net/publication/321992616_Enhancing_the_Function_Analysis_and_Identific ation_Phase_of_the_Value_Engineering_Methodology 